\title{
Promotions, Dismissals, and Employee Selection: Theory and Evidence
}

\author{
Anders Frederiksen* \\ Aarhus University \\ Előd Takáts** \\ International Monetary Fund
}

Firms offer highly complex contracts to their employees. These contracts contain a mix of incentives, such as fixed wages, bonus payments, promotion options, and dismissals or threats of dismissal. In this article, we show that firms having a production process that is sensitive to employee quality may find it optimal to combine cost-efficient incentives such as bonuses and promotions with dismissals. Based on this result, we derive a hierarchy of incentives. Furthermore, we demonstrate the close link between the optimal contract and the employee sorting and selection and use this to analyse the information conveyed in employment matches. (JEL J30, J41, M50)

\section{Motivation}

Firms use a variety of economic incentives to motivate their employees. The observed incentive mix often contains fixed salaries, bonus payments, promotion options, and dismissals or threats of dismissal. In general, economists understand why firms choose each element of the incentive mix but not why firms prefer a specific mix or what the consequences are of using a particular mix of incentives.

\footnotetext{
* Department of Marketing and Statistics, Aarhus School of Business, Aarhus University. Email: afr@asb.dk.

** International Monetary Fund. Email: etakats@imf.org.

This research project has been supported financially by The Danish Social Science Research Council through a grant to Center for Corporate Performance (CCP). Előd Takáts is grateful for financial support from the Gregory C. Chow Econometric Research Program. Anne Raaby Olsen has provided valuable research assistance.

We thank Ann Bartel, Francine Blau, Patrick Bolton, Hank Farber, Jeremy Fox, Mike Gibbs, Bo Honoré, Larry Kahn, Eddie Lazear, Bentley MacLeod, Jesse Rothstein, Kathryn Shaw, Niels Westergaard-Nielsen, Julie Wolf, two anonymous referees, and workshop and conference participants at NBER, UC Berkeley, Princeton University, Hoover Institution, CCP, the European Economic Association Amsterdam Conference, the First Annual IZA Workshop on Behavioral and Organizational Economics, and the 12th Panel Data Conference at the Center for Applied Microeconometrics for comments.
}

The Journal of Law, Economics, \& Organization, Vol. 27, No. 1, doi:10.1093/jleo/ewp017

Advance Access publication August 3, 2009

(C) The Author 2009. Published by Oxford University Press on behalf of Yale University.

All rights reserved. For Permissions, please email: journals.permissions@oxfordjournals.org 
In this article, we first present a theoretical model of how incentives are used in firms. Our main finding is that firms with production technology sensitive to the quality of the workforce may find it optimal to combine cost-efficient incentives such as bonus payments and promotions with dismissals. Consequently, quality-concerned firms operating in heavily regulated labor markets where the use of dismissals is highly restricted or very costly will face a comparative disadvantage when competing internationally.

The second important finding is that the contract offered to employees, and in particular the use of promotions and dismissals, has profound implications for the information structure in the market. Previous research has shown that, when firms sort and select their employees based on performance, observed promotion is a positive ability signal (Waldman 1984) and dismissals a negative signal of ability, unless the employee is part of an exogenous firm closure (Gibbons and Katz 1991). Our model complements this literature and allows for a deeper analysis of the information conveyed in employment matches where the employee stays with the firm but is successively passed over for promotion.

Although the existing literature argues that selection on job tenure is negative (Medoff and Abraham 1980, 1981; Lazear 1992; Gibbs 1995), we can show that both positive and negative selection may arise in a theoretical context and that the selection scheme depends critically on how the firm sets the optimal contract. The relevance of distinguishing between positive and negative selection is emphasized further in the empirical part of the article where we use the personnel records from a private company and produce a counterexample to the existing empirical literature by identifying the firm's selection scheme to be positive. This implies that inference about employee quality based on job tenure requires detailed information about the employment contract.

It is important to point out that our analysis focuses on optimal contracting and selection on job tenure. Other important research has analyzed the returns to (tenure) seniority with the firm. Even though the literature recognizes that the relation between tenure and earnings is positive, there is no consensus about the steepness of the tenure gradient, see, for instance, Abraham and Farber (1987), Altonji and Shakotko (1987) and Topel (1991). Our results fit well into the discussion and may shed some light on why consensus has not been achieved. The reason is that whereas positive selection on job tenure trivially leads to an increasing earnings profile, negative selection on job tenure requires promotions and a management premium to generate a positive relation between tenure and earnings.

The evidence that firms offer a mix of incentives to their employees is accumulating, see Medoff and Abraham (1980, 1981), Baker et al. (1994a, 1994b), Gibbs (1995), Farrall and Shearer (1999), and Lazear (1992, 2000). Nevertheless, conventional economic theory has addressed the various incentive mechanisms in separate frameworks. First, the performance-pay literature originating from Mirrlees $(1974,1976)$ and Holmström $(1979,1982)$ explains why pay, in the form of bonuses or piece rate, should be linked to output. Second, the efficiency wage literature starting with Shapiro and Stiglitz (1984) emphasizes 
the incentive effect of dismissals or the threat of dismissals. Third, tournament theory, initiated by Lazear and Rosen (1981), shows that a preset number of rewards can provide incentives to exert effort via competition. In principle, tournament theory explains why firms would use any element of the incentive mix but not the mix itself.

MacLeod and Malcolmson (1998) analyze the relative merits of different incentive tools in a single framework. They contrast efficiency wage and performance-pay incentives, that is, dismissals and bonus payments, as incentive tools. Under the efficiency wage system, firms pay rents ex ante and provide incentives by dismissing shirking workers. Under the performance-pay regime, firms pay bonuses ex post, conditional on effort. The model shows that efficiency-wage incentives are generally more expensive. Yet, if the firm cannot commit to pay bonuses, efficiency wages might be the only way to motivate employees because they give compensation up front. The results, however, do not answer the question why the observed incentive mix arises.

We propose a theoretical model where the firm has the option to offer the full incentive mix of fixed salaries, bonus payments, promotion options, and dismissal threats to its employees. When the profit maximizing and qualityconcerned firm faces a set of heterogeneous employees, sorting and selection issues become crucial (in addition to incentives) because the overall productivity of the firm depends on the quality of its employees and their job assignment. Dismissing lower quality employees is essential to improve employee quality. However, dismissals are costly for both the firm (recruiting and training of new employees) and the employees (job search), and in equilibrium, the firm shoulders all these costs. This creates a trade-off for the firm: Increased use of dismissals induces additional costs, but simultaneously, it increases employee quality. This trade-off explains why the firm prefers to use the delicate mix of incentives observed in data.

The theoretical model proposes a hierarchy of incentives. Incentives through promotions and dismissals are exhausted first because besides creating incentives, they contribute to employee sorting and selection. Bonus payments are only used to fill residual incentive needs, if any.

In the empirical part of the article, we describe the incentive contracts offered by the firm to its employees. The firm employs knowledge workers and production workers. All employees receive a fixed salary and have positive promotion and dismissal probabilities, but only knowledge workers have bonus options. This finding is consistent with our model as bonus payments are residual incentives and for that reason may drop out of the contract if promotions and dismissals provide sufficient incentives.

We also establish that the firm has performance-based sorting and that the selection scheme in the firm is positive in job tenure. Finally, we show that the earnings profile is consistent with positive selection on job tenure. Thus, as Guasch and Weiss (1980) suggest, sorting and selection constitute an interesting alternative to on-the-job human-capital acquisition in explaining the effects of tenure on earnings. In fact, selection alone can justify the positively sloped earnings profile with tenure. 
The model is outlined in the next section. The data are presented in Section 3, where we also discuss the empirical contract within the context of the theoretical model. In Section 4, we conduct the empirical analysis. Finally, Section 5 summarizes and concludes.

\section{The Model}

In this section, we present a theoretical model in which the firm has the option to offer a contract containing a fixed salary, bonus payments, promotion options, and dismissal threats to a group of heterogeneous employees. The model entails the contracting relationship between a risk-neutral firm and a continuum of risk-neutral employees in a two-period game. The firm and the employees form a principal-agent relationship. The firm maximizes expected profit, whereas the employees maximize their expected utility.

In the first period, the firm offers an employment contract in terms of fixed salaries, bonus payments, promotions, and dismissals. The timing of events is as follows:

1. The firm offers a contract to prospective employees. If they accept it, they are hired.

2. Employees decide about the effort level, which is not observed by the firm.

3. Output is realized and observed by all.

4. Bonuses are paid; some employees are promoted or dismissed.

The second period captures the "long-run" consequences of the first period job assignment decisions, that is, the consequences of promoting and dismissing a proportion of the employees. This implies that in the second period, the firm has to replace employees leaving the nonmanagement level due to dismissals and promotions, and it has to fill management vacancies. To maintain focus, we assume that employees produce output in the second period without an explicit incentive problem.

The employees produce binary output in the first period, which is normalized to 0 (low) or $C$ (high), where $C>0$. Potential employees are heterogeneous. There are good employees $(G)$ with high ability and bad ones $(B)$ with low ability. Good employees are more likely to produce high output compared with bad employees, that is, $\theta_{\mathrm{G}}>\theta_{\mathrm{B}}$, and naturally $\theta_{\mathrm{G}}, \theta_{\mathrm{B}} \in(0,1)$. However, neither the firm nor the employee is able to observe the ability of the employee. ${ }^{1}$

The firm's external labor market consists of a proportion $\mu$ of high-ability individuals. Since the firm can use promotions and dismissals to sort and select employees in the first period, the second-period employee composition may

1. Mutually unknown ability can be thought of as modeling fresh college graduates entering a firm. The graduates might not have a significant information advantage because they do not know the actual work environment. In this respect, our setup differs from Lazear $(1986,2000)$ and Lazear and Shaw (2008) who use performance pay as a mechanism for high-productivity employees (who know their productive ability) to self-select into firms with incentive pay. 
differ from the composition in the external labor market. For this reason, the proportion of high-ability types in the second period in nonmanagement is denoted by $\mu_{\mathrm{N}}$ and the proportion of high-ability types in management is $\mu_{\mathrm{M}}$. Of course, the values taken by $\mu_{\mathrm{N}}$ and $\mu_{\mathrm{M}}$ will depend on the equilibrium contract offered by the firm. Similarly, the perceived quality of dismissed employees is denoted by $\mu_{\mathrm{D}}$. For the sake of simplicity, the total value of employees' compensation must weakly exceed the compensation offered by outside firms, which is assumed to be a linear function of the employees' perceived quality, formally: ${ }^{2}$

$\bar{U}=\bar{w} \mu$,

$\bar{U}_{\mathrm{M}}=\bar{w} \mu_{\mathrm{M}}$,

$\bar{U}_{\mathrm{N}}=\bar{w} \mu_{\mathrm{N}}$

$\bar{U}_{\mathrm{D}}=\bar{w} \mu_{\mathrm{D}}$

Note that $\bar{w}$ can also be thought of as the salary paid to an employee who is known to be of high ability (and where the salary paid to an employee known to be of low ability is normalized to 0 ).

The employee, once having accepted the job, can influence the probability of high output by exerting effort. The utility cost of effort exertion is $e$, and the effort increases the probability of success by $\delta \in(0,1)$. The table below summarizes the probabilities:

\section{Without effort With effort}

$\begin{array}{lll}\text { Low output (0) } & 1-\theta_{\mathrm{B} / \mathrm{G}} & 1-\theta_{\mathrm{B} / \mathrm{G}}-\delta \\ \text { High output }(C) & \theta_{\mathrm{B} / \mathrm{G}} & \theta_{\mathrm{B} / \mathrm{G}}+\delta .\end{array}$

The effort is worth undertaking, that is, the private costs of effort are strictly less than the expected production gains, formally:

$e<\delta C$.

We will focus on the parameter setup when the first best effort level can be implemented. For completeness, we assume that $\theta_{\mathrm{G}}+\delta<1$.

Furthermore, we assume that the direct utility cost from being dismissed is $D>0$, whereas there is no direct change in utility if the employee stays with the firm in the same rank. However, if promotions or staying in the same job increase the employee's perceived quality, then the employee's overall compensation will improve. Similarly, if being dismissed or staying in the same job decreases perceived quality, compensation will fall. The change in perceived quality of staying in a job is discussed in detail below. It follows that the utility gain of a promotion can be expressed as:

$\bar{U}_{\mathrm{M}}-\bar{U}_{\mathrm{N}}$,

2. Note that these arguments are similar to Waldman (1984) and Gibbons and Katz (1991). 
the utility gain (or loss) of staying at the firm in the same rank is

$\bar{U}_{\mathrm{N}}-\bar{U}$

and the utility loss from dismissals is:

$-D-\left(\bar{U}_{\mathrm{N}}-\bar{U}_{\mathrm{D}}\right)$.

The firm sets the first-period employment contract through the following four variables: $\left\{w, b, \pi_{\mathrm{P}}, \pi_{\mathrm{D}}\right\}$. First, a fixed salary $(w)$ is offered to all individuals who accept the job, irrespective of performance. The remaining three parameters are conditional on performance. It is assumed that bonus payments (b) are paid to well-performing agents, employees with high observable output (high performance) are considered for promotion and employees with low observed output (low performance) are at risk of being dismissed. The conditional promotion probability and the conditional dismissal probability are denoted by $\pi_{\mathrm{P}}$ and $\pi_{\mathrm{D}}$, respectively. The parameters are constrained as follows: $w, b \geqslant 0$; $\pi_{\mathrm{D}}, \pi_{\mathrm{P}} \in[0,1]$. $^{3}$

Finally, turnover is costly because it imposes training and recruiting costs on the firm. These costs are summarized in the turnover cost parameter $K>0$.

In the second period, the firm has two hierarchical ranks: nonmanagement and management. The managerial rank opens for hiring in the second period, and the firm promotes from within the firm. The number of employees who can be promoted is given by the number of vacant positions in management. That is, the volume of promotions $\left(\theta_{\mathrm{B}}+\mu\left(\theta_{\mathrm{G}}-\theta_{\mathrm{B}}\right)+\delta\right) \pi_{\mathrm{P}}$ is constrained by the volume of exogenous job openings at the managerial level, which is normalized to $1 / H$. Parameter $H$ can be interpreted as the hierarchical size difference between nonmanagement and management rank. Thus,

$$
\left(\theta_{\mathrm{B}}+\mu\left(\theta_{\mathrm{G}}-\theta_{\mathrm{B}}\right)+\delta\right) \pi_{\mathrm{P}}=\frac{1}{H}
$$

For completeness, it is assumed that $\theta_{\mathrm{B}}+\mu\left(\theta_{\mathrm{G}}-\theta_{\mathrm{B}}\right)+\delta \leqslant H$ implying that the promotion probability is well defined.

The second period setup is stylized to focus on the incentive and selection problem of the first period. In the second period, employees' output is a function of the equilibrium quality: $F\left(\mu_{\mathrm{N}}\right)$, where $F(0)=0, F^{\prime}>\bar{w}$ (which guarantees that firms prefer better quality employees ceteris paribus) and $F^{\prime \prime}<0$. Managerial incentives are not modeled explicitly; their contribution to the firm's profit is assumed to be a linear function of their quality: $M \mu_{\mathrm{M}}$. We assume that $F(x)<M: \forall x \in(0,1)$, that is, managerial output is more important than employee output. This condition reflects that managers affect the output of multiple nonmanagement employees.

To keep the analysis tractable, it is assumed that the firm has all the bargaining power. Furthermore, two tiebreaking rules are imposed. First, indifferent

3. Conditioning bonus, promotion, and dismissals on output, as above, can be done without the loss of generality, which can be seen straighforwardly. Furthermore, the continuum of employees makes the contract easily enforcible, even with noninteger probabilities. 


\begin{tabular}{ll}
\hline$\{0, C\}$ & Output realizations \\
$M$ & Managerial output \\
$F\left(\mu_{N}\right)$ & Nonmanagement output in the second period \\
$\theta_{B}, \theta_{G}$ & Probability that output is high (for bad- and good quality employees) \\
$\delta$ & Performance increase with effort \\
$e$ & Effort cost \\
$\bar{W}$ & Salary paid to an employee when known to be of good quality \\
$D$ & Direct utility cost from dismissal \\
$H$ & Hierarchical size ratio of management to nonmanagement \\
$K$ & Cost of turnover \\
$W$ & Fixed salary \\
$b$ & Bonus paid conditional on high output \\
$\pi_{P}$ & Probability of promotion conditional on high output \\
$\pi_{D}$ & Probability of dismissal conditional on low output \\
\hline
\end{tabular}

players act such that the other player is better off. Second, employees are assumed to prefer less risky payments with the same mean as a form of moderate risk aversion. Finally, we focus on parameter values where the firm is profitable, that is, it engages in production and hires employees. The model's parameters are presented in Table 1.

\subsection{The Optimization Problem}

Based on the preceding discussion, we can formally present the firm's contracting problem as a constrained profit maximization problem:

$$
\begin{aligned}
\max _{w, b, \pi_{\mathrm{D}}, \pi_{\mathrm{P}}} \quad\left(\theta_{\mathrm{B}}\right. & \left.+\mu\left(\theta_{\mathrm{G}}-\theta_{\mathrm{B}}\right)+\delta\right)(C-b)-w \\
& -\left(1-\theta_{\mathrm{B}}-\mu\left(\theta_{\mathrm{G}}-\theta_{\mathrm{B}}\right)-\delta\right) \pi_{\mathrm{D}} K \\
& +\frac{M-\bar{w}}{H} \mu_{\mathrm{M}}+F\left(\mu_{\mathrm{N}}\right)-\bar{w} \mu_{\mathrm{N}}-\frac{K}{H}
\end{aligned}
$$

subject to

$$
\begin{gathered}
w-e+\bar{U}_{\mathrm{N}}-\bar{U}+\left(\theta_{\mathrm{B}}+\mu\left(\theta_{\mathrm{G}}-\theta_{\mathrm{B}}\right)+\delta\right)\left[b+\pi_{\mathrm{P}}\left(\bar{U}_{\mathrm{M}}-\bar{U}_{\mathrm{N}}\right)\right] \\
-\left(1-\theta_{\mathrm{B}}-\mu\left(\theta_{\mathrm{G}}-\theta_{\mathrm{B}}\right)-\delta\right) \pi_{\mathrm{D}}\left[D+\left(\bar{U}_{\mathrm{N}}-\bar{U}_{\mathrm{D}}\right)\right] \geqslant \bar{U} \\
\delta\left[b+\pi_{\mathrm{P}}\left(\bar{U}_{\mathrm{M}}-\bar{U}_{\mathrm{N}}\right)+\pi_{\mathrm{D}}\left(D+\left(\bar{U}_{\mathrm{N}}-\bar{U}_{\mathrm{D}}\right)\right)\right] \geqslant e
\end{gathered}
$$

promotion

$$
\left(\theta_{\mathrm{B}}+\mu\left(\theta_{\mathrm{G}}-\theta_{\mathrm{B}}\right)+\delta\right) \pi_{\mathrm{P}} \leqslant \frac{1}{H}
$$

nonnegativity

$$
0 \leqslant w, b
$$

probability

$$
\pi_{\mathrm{D}}, \pi_{\mathrm{P}} \in[0,1],
$$

where $\bar{U}, \bar{U}_{\mathrm{M}}, \bar{U}_{\mathrm{N}}$, and $\bar{U}_{\mathrm{D}}$ are as defined in (1), (2), (3), and (4), respectively. 
The firm's profitability can be seen straightforwardly in (6). First, employees contribute to profits by providing the high output $C$ with probability $\theta_{\mathrm{B}}+$ $\mu\left(\theta_{\mathrm{G}}-\theta_{\mathrm{B}}\right)+\delta$ in the first period. However, in case of high output, the firm also pays out bonus payments $b$. Profitability is also reduced by the fixed salary $w$. Furthermore, the firm has to hire new workers in place of dismissed bad performers at cost $K$. The volume of dismissed employees is given by the probability of low output $1-\theta_{\mathrm{B}}-\mu\left(\theta_{\mathrm{G}}-\theta_{\mathrm{B}}\right)-\delta$ and the likelihood of dismissal given low output $\pi_{\mathrm{D}}$.

In the second period, managers and employees both contribute to firm profitability. Each good quality manager contributes to profit by $M$. The number of managers is $1 / H$ and the proportion of good quality is $\mu_{\mathrm{M}}$. Managers' pay depends on their equilibrium quality: $\bar{w} \mu_{\mathrm{M}}$. The productivity of nonmanagement employees also depends on quality: $F\left(\mu_{\mathrm{N}}\right)$ and they are paid $\bar{w} \mu_{\mathrm{N}}$. Finally, the firm has to hire the volume $1 / H$ new employees at cost $K$ to fill managerial vacancies.

The individual rationality constraint (IR) states that employees weakly prefer accepting the contract. The left-hand side of the equation states the utility of accepting the job offer. The employee receives the fixed salary $(w)$ and incurs the cost of effort $(e)$. Employees who can stay on at the firm in the nonmanagerial rank receive utility $\bar{U}_{\mathrm{N}}-\bar{U}$. All utility gains from promotion and losses from dismissals will be compared with this baseline. Furthermore, the probability $\left(\theta_{\mathrm{B}}+\mu\left(\theta_{\mathrm{G}}-\theta_{\mathrm{B}}\right)+\delta\right)$ of high output leads to bonus payments $(b)$ and chances for promotion $\left(\pi_{\mathrm{P}}\right)$, which provides $\left(\bar{U}_{\mathrm{M}}-\bar{U}_{\mathrm{N}}\right)$ utility in equilibrium. Also, the employee has some risk $\left(1-\theta_{\mathrm{B}}-\mu\left(\theta_{\mathrm{G}}-\theta_{\mathrm{B}}\right)-\delta\right) \pi_{\mathrm{D}}$ of being dismissed and hereby incurring the disutility $\left(D+\bar{U}_{\mathrm{N}}-\bar{U}_{\mathrm{D}}\right)$. The right-hand side shows the worker's alternative compensation $(\bar{U})$.

The incentive compatibility constraint (IC) implies that the employee accepting the contract is better off by exerting the first-best high effort in the first period. The benefits of high effort (on the left-hand side) must exceed the cost of effort $(e)$ on the right-hand side. High effort increases the probability of high output by $\delta$. Conditional on high-output employees receive bonus payments $(b)$, have a chance $\left(\pi_{\mathrm{P}}\right)$ for valued $\left(\bar{U}_{\mathrm{M}}-\bar{U}_{\mathrm{N}}\right)$ promotion, and avoid costly $\left(D+\bar{U}_{\mathrm{N}}-\bar{U}_{\mathrm{D}}\right)$ dismissals relating to low performance $\left(\pi_{\mathrm{D}}\right)$.

The promotion constraint simply states that the firm cannot promote more high-performing employees $\left(\theta_{\mathrm{B}}+\mu\left(\theta_{\mathrm{G}}-\theta_{\mathrm{B}}\right)+\delta\right) \pi_{\mathrm{P}}$ than the number of managerial vacancies $(1 / H)$.

\subsection{Solving the Problem}

We solve the problem in three main steps. First, we derive the equilibrium quality of staying, dismissed, and promoted employees in Lemma (1).

Lemma 1. In the second period, the equilibrium proportion of good workers in nonmanagement $\left(\mu_{\mathrm{N}}\right)$ depends on the dismissal and promotion probabilities:

$$
\mu_{\mathrm{N}}=\mu+\mu(1-\mu)\left(\theta_{\mathrm{G}}-\theta_{\mathrm{B}}\right)\left(\pi_{\mathrm{D}}-\pi_{\mathrm{P}}\right) .
$$


The proportion of good quality workers in management $\left(\mu_{M}\right)$ is determined as:

$$
\mu_{\mathrm{M}}=\frac{\mu\left(\theta_{\mathrm{G}}+\delta\right)}{\theta_{\mathrm{B}}+\mu\left(\theta_{\mathrm{G}}-\theta_{\mathrm{B}}\right)+\delta} .
$$

The proportion of good quality employees among the dismissed employees $\left(\mu_{\mathrm{D}}\right)$ is given by:

$$
\mu_{\mathrm{D}}=\frac{\mu\left(1-\theta_{\mathrm{G}}-\delta\right)}{1-\theta_{\mathrm{B}}-\mu\left(\theta_{\mathrm{G}}-\theta_{\mathrm{B}}\right)-\delta} .
$$

Proof. Consider second-period employee quality $\left(\mu_{\mathrm{N}}\right)$ first. Note that establishing the volume of good quality employees determines employee quality because the firm employs a unit volume of employees. Thus, the equilibrium proportion can be determined as the sum of good employees newly hired into nonmanagement and the number of good employees surviving to the second period.

$$
\begin{aligned}
\mu_{\mathrm{N}}= & \underbrace{\overbrace{\left(\left(1-\theta_{\mathrm{B}}-\mu\left(\theta_{\mathrm{G}}-\theta_{\mathrm{B}}\right)-\delta\right) \pi_{\mathrm{D}}+\left(\theta_{\mathrm{B}}+\mu\left(\theta_{\mathrm{G}}-\theta_{\mathrm{B}}\right)+\delta\right)\right)}^{\text {newly hired in the second period }}}_{\text {newly hired in the second period of good quality }} \\
& +\underbrace{\mu-\left(1-\theta_{\mathrm{G}}-\delta\right) \mu \pi_{\mathrm{D}}-\left(\theta_{\mathrm{G}}+\delta\right) \mu \pi_{\mathrm{P}}}_{\text {good quality employees surviving to the second period }} .
\end{aligned}
$$

Straightforward simplification yields the result in equation (7).

For $\mu_{\mathrm{M}}$, compare the number of good quality high performers promoted $\mu\left(\theta_{\mathrm{G}}+\delta\right) H \pi_{\mathrm{P}}$ to the number of all promoted employees

$\left(\theta_{\mathrm{B}}+\mu\left(\theta_{\mathrm{G}}-\theta_{\mathrm{B}}\right)+\delta\right) H \pi_{\mathrm{P}}$.

Similarly, for $\mu_{\mathrm{D}}$, compare the number of high-quality employees dismissed $\mu\left(1-\theta_{\mathrm{G}}-\delta\right) \pi_{\mathrm{D}}$ to the total number of employees dismissed

$\left(1-\theta_{\mathrm{B}}-\mu\left(\theta_{\mathrm{G}}-\theta_{\mathrm{B}}\right)-\delta\right) \pi_{\mathrm{D}}$.

Second, we note that the full incentive mix of fixed salary, bonus payments, promotions, and dismissals can only arise if the IR and IC constraints are binding. Either the IR constraint binds or the salary is set to 0 in the profitmaximizing equilibrium. If it does not bind, the salary must be 0 or else the firm would reduce the fixed salary and thereby increase its profit. Similarly, the IC binds or the bonus is set to 0 in equilibrium. If the IC constraint does not bind, the bonus must be 0 or else the firm would decrease bonus payments. Hence, we can focus on the equilibrium where all three constraints bind.

Third, we rewrite the problem as a function of the dismissal probability assuming (and later verifying) that all three constraints are binding. It follows that the profit-maximizing first-order condition with respect to $\pi_{D}$ can be 
expressed as:

$$
\begin{aligned}
\frac{\partial F\left(\mu_{\mathrm{N}}^{\prime}\right)}{\partial \mu_{\mathrm{N}}} \mu(1-\mu)\left(\theta_{\mathrm{G}}-\theta_{\mathrm{B}}\right)= & {\left[1-\theta_{\mathrm{B}}-\mu\left(\theta_{\mathrm{G}}-\theta_{\mathrm{B}}\right)-\delta\right](D+K) } \\
& +\mu(1-\mu)\left(\theta_{\mathrm{G}}-\theta_{\mathrm{B}}\right) \bar{w},
\end{aligned}
$$

where

$\mu_{\mathrm{N}}^{\prime}=\mu+\mu(1-\mu)\left(\theta_{\mathrm{G}}-\theta_{\mathrm{B}}\right)\left(\pi_{\mathrm{D}}-\frac{1}{H\left(\theta_{\mathrm{B}}+\mu\left(\theta_{\mathrm{G}}-\theta_{\mathrm{B}}\right)+\delta\right)}\right)$.

The left-hand side of equation (10) summarizes the gains from dismissals. These gains are indirect and stem from improved employee quality in the second period. The term

$$
\frac{\partial F}{\partial \mu_{\mathrm{N}}}>0
$$

shows that the marginal sensitivity of the production function to employee quality increases the attractiveness of dismissals. Furthermore, the positive effect is larger when employee heterogeneity is high, that is, when both the quality differences $\left(\theta_{\mathrm{G}}-\theta_{\mathrm{B}}\right)$ and the variance in workforce quality $\mu(1-\mu)$ are high.

The right-hand side of equation (10) summarizes the costs of dismissals. First, employees need compensation to offset expected job search costs $D$. Furthermore, the firm also incurs turnover costs $K$. Second, firing improves equilibrium employee quality, which in turn increases compensation needs. The third and last terms summarizes the compensation costs of having a better qualified workforce within the firm.

The first-order condition shows that dismissals are not necessarily set to zero. Hence, the observed incentive mix arises in the following case: First, the optimal dismissal rate implied by equation (10) is strictly positive (remember that promotion occur due to the binding promotion constraint). Second, the firm pays positive bonuses only if promotions and dismissals do not provide strong enough incentives. Third, the firm pays positive salaries only if promotions, dismissals, and bonuses do not compensate sufficiently relatively to the outside job offer. Lemma (2) summarizes the result.

Lemma 2. The observed incentive mix of fixed salaries, bonus payments, promotions, and dismissals arises in equilibrium if the following three conditions are satisfied: First, $\pi_{\mathrm{D}}^{\prime}$ implied by equation (10) is strictly positive. Then, $\pi_{\mathrm{D}}^{*}=\min \left\{\pi_{\mathrm{D}}^{\prime}, 1\right\}$. Second, promotions implied by binding promotion constraint:

$\pi_{\mathrm{P}}^{*}=\frac{1}{H\left(\theta_{\mathrm{B}}+\mu\left(\theta_{\mathrm{G}}-\theta_{\mathrm{B}}\right)+\delta\right)}$,

and $\pi_{\mathrm{D}}^{*}$ does not provide enough incentives, so positive bonuses $\left(b^{*}\right)$ are needed:

$$
b^{*}=\frac{e}{\delta}-\pi_{\mathrm{P}}^{*}\left(\bar{U}_{\mathrm{M}}^{*}-\bar{U}_{\mathrm{N}}^{*}\right)-\pi_{\mathrm{D}}
$$

where $D>0$ 
where

$$
\begin{aligned}
\bar{U}_{\mathrm{M}}^{*} & =\bar{w} \frac{\mu\left(\theta_{\mathrm{G}}+\delta\right)}{\theta_{\mathrm{B}}+\mu\left(\theta_{\mathrm{G}}-\theta_{\mathrm{B}}\right)+\delta}, \\
\bar{U}_{\mathrm{N}}^{*} & =\bar{w}\left[\mu+\mu(1-\mu)\left(\theta_{\mathrm{G}}-\theta_{\mathrm{B}}\right)\left(\pi_{\mathrm{D}}-\pi_{\mathrm{P}}^{*}\right)\right] .
\end{aligned}
$$

Third, with $\pi_{\mathrm{P}}^{*}, \pi_{\mathrm{D}}, b^{*}$, and positive fixed salaries $\left(w^{*}\right)$ are required for employees to accept the contract

$$
\begin{aligned}
w^{*}=\bar{U} & -\left(\theta_{\mathrm{B}}+\mu\left(\theta_{\mathrm{G}}-\theta_{\mathrm{B}}\right)\right)\left(b^{*}+\pi_{\mathrm{P}}^{*}\left(\bar{U}_{\mathrm{M}}^{*}-\bar{U}_{\mathrm{N}}^{*}\right)\right) \\
& +\left(1-\theta_{\mathrm{B}}-\mu\left(\theta_{\mathrm{G}}-\theta_{\mathrm{B}}\right)\right) \pi_{\mathrm{D}} \quad \text { where } D>0 .
\end{aligned}
$$

Proof. The proof of the lemma follows from the discussion preceding it. It is straightforward to show parameter values where the incentive mix arises and it is left to the reader.

The results in Lemma (2) are explicit about the hierarchy of incentives: promotions and dismissals are used first. If additional incentives are required, they are provided through bonuses. Finally, salaries are only used to make the employee accept the firm's offer.

It may also be interesting to note that when employees are homogeneous in quality only, bonus payments can be used to elicit effort from the employees. The reason is that an employee's perceived quality is unaltered by sorting and selection, which implies no managerial rent and no reason to dismiss lowperforming employees. Thus, it will be suboptimal for the firm to use costly dismissals, but promotions will be observed when the firm has vacancies in management. However, these promotions are not valued and do not provide incentives, as there is no signaling of quality.

\subsection{Selection}

The employment contract has profound implications for the firm's internal dynamics and the information conveyed in the employment match. The reason is that the conditional promotion and dismissal probabilities $\left(\pi_{\mathrm{P}}\right.$ and $\left.\pi_{\mathrm{D}}\right)$ affect the workforce composition in the firm, as is established in Lemma (1). Furthermore, because high- and low-ability employees differ in their expected productivity, the ongoing sorting and selection also affect the individual's employment prospects.

To fully understand the consequences of the optimal contract, we will formally characterize the firm's selection regime and state conditions under which a particular selection regime will arise. We will use that definition that selection on job tenure is negative when the quality of the workforce decreases with time on the job and otherwise selection on job tenure is positive.

Definition 1. When the quality of the workforce decreases with job tenure, the firm has negative selection on job tenure; otherwise selection on job tenure is positive. 
The contract implies that a proportion of the employees with high performance (who are more likely to be high-ability employees) are promoted out of nonmanagement each period. This will naturally imply that the quality of the group of employees passed over for promotion declines with job tenure. However, the picture may change if the firm dismisses a sufficiently large proportion of employees with low performance (who are more likely to be low-ability employees). In fact, if dismissals are used sufficiently frequent, the quality of the workforce improves, and positive selection on job tenure arises. The intuition is formalized in Corollary (1).

Corollary 1. Firms using performance-based sorting have positive selection in rank:

$\mu_{\mathrm{M}}>\mu$.

Selection on job tenure is positive, that is,

$\mu_{\mathrm{N}}>\mu$,

if

$\pi_{\mathrm{P}}<\pi_{\mathrm{D}}$

and negative if

$\pi_{\mathrm{P}}>\pi_{\mathrm{D}}$

The close link between the selection regime and the employees careers' has been established in previous research, but the focus has exclusively been on negative selection, see Medoff and Abraham (1980, 1981), Lazear (1992), and Gibbs (1995). For instance, based on a series of empirical findings, Medoff and Abraham $(1980,1981)$ wrote " _... the negative within-grade-level correlation, which we suspect exists between experience and ability." Lazear (1992) continues this discussion, arguing that "Individuals who remain on the job longer, do worse than those who are promoted out early. Wages actually decline with job tenure, probably reflecting the fall in the average worker's quality with length of time in the job." In terms of our model, these statements can be interpreted as negative selection. A more detailed discussion is given in Gibbs (1995) who argues that "... employees are continuously selected out through promotions, demotions, or exits. Because of these selection effects, ability of the group should decline with tenure..." In contrast to the earlier examples, Gibbs recognizes that the selection process is affected by dismissals but that does not change the conclusion that selection on job tenure is negative.

From our discussion, it becomes clear that negative selection on job tenure is a possibility, but not a rule. If the conditional dismissal probability exceeds the conditional promotion probability, the selection scheme on job tenure shifts from negative to positive. As it will turn out in the empirical analysis conducted below, our firm has a positive selection on job tenure, which provides 


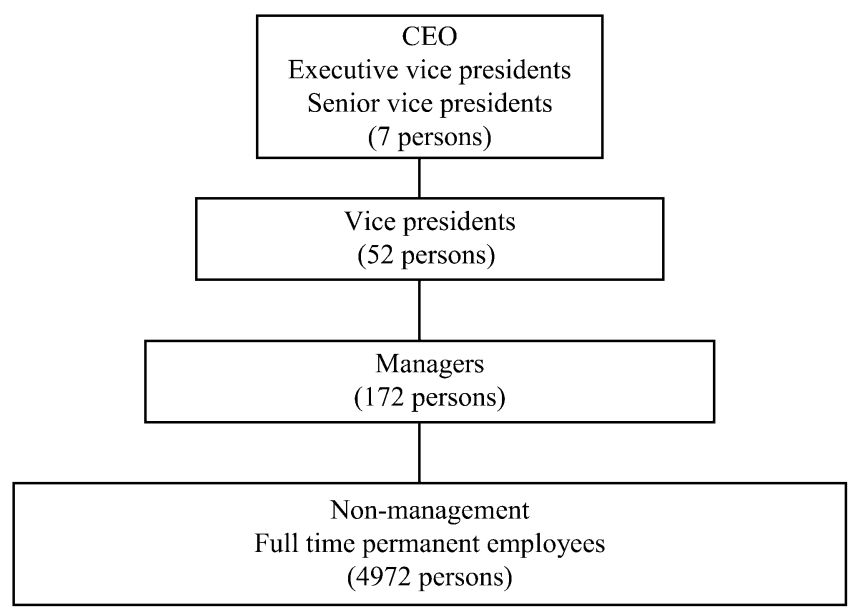

Figure 1. The Hierarchy of the Firm.

a counterexample to the earlier conclusions drawn about negative selection in the literature.

\section{Data}

In this section, we describe the data and discuss the empirical contract. Four years (1997-2000) of personnel records from the main production site of an international pharmaceutical company are used in the empirical analysis. Average employment is 5203 full-time workers. ${ }^{4}$ These workers are distributed across four hierarchical levels ranging from CEO to nonmanagement (see Figure 1). The share of management workers in the firm is $4.5 \%$.

The employee characteristics are presented in Table 2. Women comprise $59 \%$ of the workforce, and the average age is 40 years. The employees have 8.5 years of tenure on average with a standard deviation of 7 .

The education level in the firm is high. ${ }^{5}$ In fact, $24 \%$ of the employees have at least a master's degree and $12 \%$ have a college degree. Only $14 \%$ of the labor force are unskilled. ${ }^{6}$ There are three reasons why this structure is observed. First, the firm is operating in an industry where product development is essential for survival, which means that a large proportion of the workforce is engaged in research and development. Second, production is highly automated, suggesting that low-skilled labor has been substituted by capital. Finally, to

4. The analysis is focused on permanent full-time employment, which corresponds to $90.45 \%$ of all individuals employed on the production site.

5. Information on education is missing for $7.44 \%$ of the employees. For knowledge workers, only $2.57 \%$ have missing information. Observations with missing information are deleted from the sample.

6. Unskilled workers have only basic levels of education such as completed primary school. Skilled workers have some formal training in addition to primary school. Workers with short theoretical educations can be thought of as laboratory workers. 


\begin{tabular}{lccc}
\hline & \multicolumn{3}{c}{ Mean (SD) } \\
\cline { 2 - 4 } & $\begin{array}{c}\text { Production } \\
\text { workers }\end{array}$ & $\begin{array}{c}\text { Knowledge } \\
\text { workers }\end{array}$ & All employees \\
\hline Age & $39.56(9.36)$ & $39.56(8.55)$ & $39.56(8.83)$ \\
Gender (women = 1) & 0.47 & 0.60 & 0.59 \\
Unskilled worker & 0.34 & 0.03 & 0.14 \\
Skilled worker & 0.56 & 0.16 & 0.30 \\
Short theoretical education & 0.06 & 0.28 & 0.21 \\
College degree & 0.03 & 0.17 & 0.12 \\
Master's or PhD degree & 0.01 & 0.35 & 0.24 \\
Tenure: 2 years or less & 0.22 & 0.19 & 0.20 \\
Tenure: 3-5 years & 0.15 & 0.15 & 0.15 \\
Tenure: 5-10 years & 0.34 & 0.29 & 0.31 \\
Tenure: 10-15 years & 0.14 & 0.19 & 0.17 \\
Tenure: $15-25$ years & 0.13 & 0.14 & 0.14 \\
Tenure: 25 years or above & 0.01 & 0.05 & 0.04 \\
Tenure & $7.44(6.08)$ & $8.91(7.43)$ & $8.41(7.03)$ \\
Observations & 6502 & 12,737 & 19,239 \\
\hline
\end{tabular}

comply with regulations from the Food and Drug Administration, extensive quality control programs requiring skilled labor are implemented.

The employees in the firm are divided into two groups: knowledge workers and production workers. The group of knowledge workers constitutes $66 \%$ of the workforce (or 12,737 employee-year observations). The contracts offered to these workers contain the full incentive mix of fixed salaries, bonus options, promotions, and dismissals. Production workers have no bonus options.

\subsection{The Empirical Contract}

According to the firm's official remuneration principles, it offers wages to the employees such that "The base salary is a competitive pay for job function, responsibilities and competencies." There are two pieces of evidence in the data, which show that this principle is taken seriously. First, entry salaries vary both within and between education groups, and both the mean and the variance are increasing in the education level. ${ }^{7}$ This means that the firm rewards employees according to their production capacity (education) but also that the firm screens the employee's competencies at entry that gives rise to different entry salaries. Second, there is a close link between observable competencies and base pay. For instance, a simple Mincer wage regression using a set of individual characteristics and information about the employee's job category produce an $R^{2}$ of 0.864 .

The hiring strategy of the firm is such that $98.33 \%$ of the employees are hired into the lowest hierarchical level. Thus, management vacancies are

7. The average wage at entry for an unskilled employee is 25,057 and the standard deviation is 2919 leading to a (standard deviation)/mean ratio of 0.12 . For skilled workers, the ratio is 0.14 and for the highest education group, the ratio is 0.20 . 


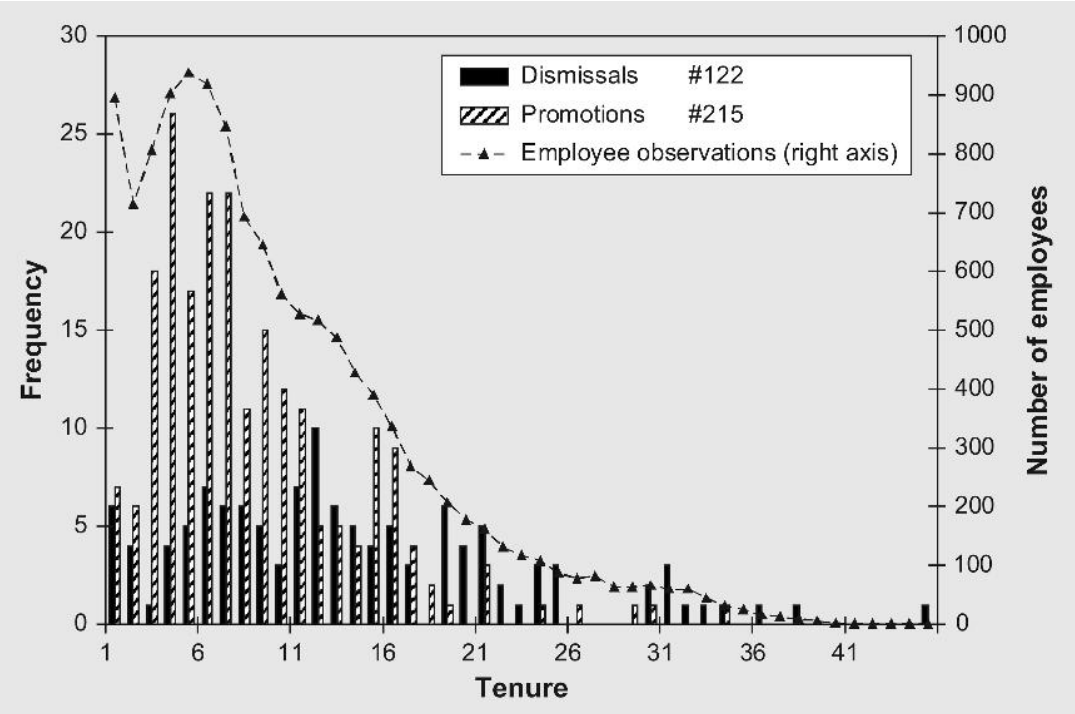

Figure 2. Dismissals and Promotions.

predominantly filled from within. The wage premium (unconditional on human capital) associated with a promotion from nonmanagement and into lower and middle management is $44 \%$ and $76 \%$, respectively. The policy of promoting from within and the associated wage gains on promotion imply that the promotion option provides strong incentives for the employees.

The institutional settings impose no restrictions on whom to lay off, and the firm seems to use dismissals frequently. The firm's yearly separation rate among its full-time permanent employees is $6 \%$. The turnover is costly for the firm, but nevertheless, more than $20 \%$ of all separations are initiated by the firm through dismissals. The picture is similar for both knowledge and production workers. Thus, dismissals is a significant component of the observed incentive mix.

Sorting and selection are of particular importance for this study. For this reason, Figure 2 presents the dismissals and promotions that have taken place in the firm by tenure. It is clear from the figure that both dismissals and promotions occur at all levels of tenure meaning that the incentive effects of promotions and dismissals are present even for employees with relatively high tenure. Naturally, it is also the case that most of the promotions and dismissals occur at low tenure levels where most employees are present. But, as we will see below, it also reflects that most sorting and selection take place early in the employee's careers.

All knowledge workers are rewarded for performance through a bonus system. The allocation of bonuses fulfills the criteria that "The principles, criteria and targets that will lead to bonus payments should be known by the relevant employee subgroup." The size of the bonus pool varies across the different 
employee subgroups and constitutes $2.5 \%-4 \%$ of the wage sum for nonmanagement workers and $8 \%$ for nonexecutive managers. The bonus system is widespread, and according to the data, $24 \%$ of the knowledge workers in nonmanagement are receiving bonus payments in a given year. The numbers are closer to $75 \%$ and $80 \%$ for managers and vice presidents, respectively. In contrast to this, production workers are not part of a bonus program. This finding is consistent with the theory because production workers face positive promotion and dismissal probabilities and given this provides sufficient incentives bonus payments will drop out of the contract as they only fill residual incentive needs.

From this presentation of the firm, it becomes clear that the contract offered to the employees is highly complex in nature. First, the firm pays fixed salaries to all workers who accept the contract. Second, knowledge workers are rewarded for performance through a bonus system. Third, even though turnover is costly for the firm, a significant part of separations are firm initiated, that is, dismissals. Finally, promotions to higher level jobs take place (mainly) from the pool of incumbent employees. In sum, the data describe a contract for knowledge workers that contains four parameters: $w, b, \pi_{\mathrm{P}}$, and $\pi_{\mathrm{D}}$.

\section{Empirical Analysis}

In this section, we establish that the firm has performance-based sorting and that the firm's selection scheme is positive in job tenure. We also show that the earnings profile is consistent with positive selection on job tenure.

To establish the firm's selection scheme, a measure of performance or a measure highly correlated with performance is required. Our empirical strategy is to use the information about bonus payments to establish if the employee had high performance, that is, if a person received a bonus $(b)$ during the preceding 12 months, the person must have had high performance. The power of using this measure over a performance scale created by subjective evaluation is that bonus payments induce costs on the firm. Thus, the firm will only signal high performance to the employees if it is indeed associated with high productivity. In contrast, firms may want to distort subjective performance evaluations without associated payments, see MacLeod (2003) for a detailed discussion. This strategy implies that the selection regime will be established only for knowledge workers.

Corollary (3) stresses that the firm's selection scheme depends on the relative magnitude of the conditional promotion and dismissal probabilities $\left(\pi_{\mathrm{P}}\right.$ and $\pi_{\mathrm{D}}$ ). We estimate the conditional probabilities using a multinomial logit model where the individual is facing three destinations: stay within rank, promotion, and dismissal. The conditional promotion and dismissal probabilities are obtained by predicting the transition probabilities from the multinomial logit regression and conditioning on having received or not having received a bonus payment during the previous year.

The results for nonmanagers are presented in Table 3 . The average predicted monthly promotion probability for employees who receive a bonus payment 
Table 3. Average Predicted Monthly Transition Probabilities (Knowledge Workers)

\begin{tabular}{lccc}
\hline & \multicolumn{3}{c}{ Destinations (\%) } \\
\cline { 2 - 4 } & Promotion & Dismissal & Stay within rank \\
\hline $\begin{array}{c}\text { Average transition probability } \\
\quad \text { sample means) }\end{array}$ & $0.146(0.146)$ & $0.101(0.101)$ & $99.753(99.753)$ \\
$\begin{array}{c}\text { Average transition probability given } \\
\text { bonus is received }\end{array}$ & 0.166 & 0.027 & \\
$\begin{array}{c}\text { Average transition probability given } \\
\text { no bonus is received }\end{array}$ & 0.091 & 0.231 \\
$\begin{array}{c}\text { Change in probability due to bonus } \\
\text { nheran }\end{array}$ & 0.075 & -0.204 & \\
\hline
\end{tabular}

(i.e., those who had high performance) is $0.166 \%$, whereas the dismissal probability is as low as $0.027 \%$. In contrast, the employees who did not receive a bonus payment (low performance) have little chance of being promoted and face a $0.231 \%$ risk of being dismissed from the firm in any given month. Hence, a bonus payment increases the promotion probability by $82 \%$ ( 0.075 percentage points) and almost eliminates the firing probability.

Based on these finding, two conclusions can be drawn. First, the firm expectedly uses performance-based sorting. Second, the selection scheme is positive in job tenure. Although the first result follows trivially from Table 3, the second result follows when observing that the conditional dismissal probability exceeds the conditional promotion probability, that is, $\pi_{\mathrm{D}}=0.231>\pi_{\mathrm{P}}=$ $0.166{ }^{8}$ The same conclusions can be made for management employees where $\pi_{\mathrm{D}}=0.013>\pi_{\mathrm{P}}=0.002$.

The theoretical model has a clear prediction about the evolution of earnings given the selection scheme. That is, positive selection predicts a positively sloped earnings profile in job tenure since $\bar{w} \mu_{\mathrm{N}}>\bar{w} \mu$. Note that this is not a trivial prediction as we focus on the earnings profile in job tenure and not the conventional Mincer wage profile. Furthermore, previous empirical research such as Lazear (1992) has shown that the earnings profile in job tenure may be decreasing which in the context of our model would be due to negative selection and $\bar{w} \mu_{\mathrm{N}}<\bar{w} \mu$. Lazear also propose that this as an explanation for his finding. Thus, a direct test of our model is to investigate if there is correspondence between the selection scheme and the earnings progression. This is done next.

In the first columns of Table 4, we focus on knowledge workers for whom we have been able to establish the selection scheme. First, we show separate regressions for fixed salary and bonus payments, and then in the third column,

8. Moreover, the positive selection might be even stronger than shown by these numbers due to a potential bias in the dismissal data. A bias arises in the case where the firm signals to the worker that the employment relation will end in the near future. This signal will make the worker look for alternative employment, which may be obtained before the firm terminates the match. From conversations with the firm, we have reason to believe that this procedure is common. The implication is that the dismissals observed in the firm only constitute a lower bound on the separations that in reality are dismissals. 


\begin{tabular}{|c|c|c|c|c|}
\hline & \multicolumn{3}{|c|}{ Knowledge workers } & Production workers \\
\hline & Fixed salary & Bonus & Earnings & Earnings \\
\hline Tenure: 2 years or less & - & - & - & - \\
\hline Tenure: $3-5$ years & $555(153)$ & $2031(644)$ & $2586(684)$ & $451(131)$ \\
\hline Tenure: $5-10$ years & $1924(168)$ & 2167 (591) & $4091(647)$ & $13(139)$ \\
\hline Tenure: $10-15$ years & $2722(198)$ & 3608 (709) & $6329(779)$ & $-385(180)$ \\
\hline Tenure: $15-25$ years & 2766 (247) & 3732 (786) & $6498(884)$ & $-46(260)$ \\
\hline Tenure: 25 years or above & $3747(385)$ & 3409 (1023) & 7156 (1192) & $-\mathbf{1 1 0 0}(452)$ \\
\hline Unskilled worker & - & - & - & - \\
\hline Skilled worker & $1254(301)$ & $972(716)$ & $2226(843)$ & $295(120)$ \\
\hline Short theoretical education & $1832(300)$ & 747 (676) & 2579 (802) & $133(253)$ \\
\hline College degree & $2086(316)$ & 1125 (889) & 3211 (1010) & $1084(366)$ \\
\hline Master's or PhD degree & $3627(387)$ & 2135 (1268) & $5762(1419)$ & $1647(883)$ \\
\hline$R^{2}$ & 0.829 & 0.363 & 0.571 & 0.283 \\
\hline Observations & 8395 & 8395 & 8395 & 6483 \\
\hline
\end{tabular}

Significant coefficients are indicated with bold. SE are clustered with respect to individuals. All measures of income are in real terms. All regressions control for job category, time, age, age squared, and gender.

we combine bonuses and fixed salaries into a measure of total earnings. As above, we only show results for nonmanagement employees. ${ }^{9}$ All three measures of compensation increase with job tenure. Thus, as hypothesized, we find close correspondence between the identified selection scheme and the earnings profile in job tenure. It is also the case that the profiles are steeper early in the career. ${ }^{10}$ This finding is consistent with existing literature on employer learning, see Farber and Gibbons (1996), Altonji and Pierret (2001), and in particular Lange (2007) who shows that most learning is completed after 3 years of employment.

We are unable to establish the selection scheme for production workers because we lack a performance measure for this group. Nevertheless, it is interesting to see that the effect of job tenure on earnings is not trivially increasing for this group, that is, the profile is first increasing then decreasing. The mixed picture for production workers combined with the evidence of an increasing earnings profile for knowledge workers and a declining earnings profile in, for example, Lazear (1992) show that selection on job tenure may differ across firms and employee subgroups and lead to very different career prospects for the involved employees. ${ }^{11}$ It also emphasizes the need to identify the firms

9. Note that the first year of data are used to construct the bonus/performance variable.

10. All tenure categories are significantly different from the reference group that has less than 3 years of tenure. However, the confidence intervals are overlapping for the higher tenure categories.

11. This finding matches well with the more general finding in Frederiksen et al. (2007) who use a large employer-employee data set and document that the job separation process is influenced by firm fixed effects. We show that variation in the employment contract across firms or employee subgroups is one motivation for the presence of these firm fixed effects. 
selection scheme before predictions about earnings progression can be made. Combined the results show as Guasch and Weiss (1980) suggests that sorting and selection constitute an interesting alternative to on-the-job human-capital acquisition in explaining the relation between earnings and tenure.

\section{Conclusions}

Firms are known to offer highly complex incentive contracts to their employees. Such contracts most often contain fixed wages, bonus payments, promotions, and dismissals. In this article, we aim at understanding why firms prefer such an incentive mix. To do so, we build a theoretical model and subsequently analyze its performance using personnel data from a private company. The key result is that firms with a production process that is sensitive to the quality of the workforce have an interest in using the full incentive mix. In particular, these firms use dismissals because it contributes to selection in addition to its incentive role.

This finding is important for two reasons. First, it shows that regulating dismissals has profound implications for firm profitability. The reason is that quality-concerned firms might want to dismiss badly performing employees, even when the level of employment is constant, to improve the quality of their workforce. Thus, labor market regulations limiting dismissals might well place these quality-concerned firms in a comparative disadvantage when competing on the international market.

Second, the presence of both promotions and dismissals in the optimal contract has important consequences for the information structure in the market. Although promotions and (individual) dismissals are strong quality signals to the market, it is less obvious what information is conveyed in employment matches for employees who stay with the firm but are continuously passed over for promotion. Our results show that this depends critically on the structure of the optimal contract. Hence, both positive and negative selections on job tenure may arise. So, it is possible to make inference about employee quality based on job tenure, but only if detailed knowledge about the employment contract is available. In fact, the selection scheme is likely to vary across firms operating in differently regulated labor markets, facing different employee compositions in terms of productive ability or applying different types of capital that imply variation in how sensitive the production process is to employee quality. This heterogeneity may be one reason no consensus is achieved in the literature on the returns to tenure.

An additional result arising from the model is a hierarchy of incentives. When firms are concerned about the quality and allocation of the workforce, promotions and dismissals play a dual role. Besides creating incentives for the employees, they also contribute to sorting and selection. This is the reason why promotions and dismissals rank at the top of the incentive hierarchy in qualityconcerned firms. Bonus payments only fulfill residual incentives and may as a consequence drop out of the optimal contract if promotions and dismissals create sufficient incentives for the employees. 
The empirical results presented in this article show a close correspondence between the firm's selection scheme and the earnings profile. Thus, our model complies with the Gibbons and Waldman (1999a, 1999b) critique, which states that many models may be able to explain a single empirical finding (such as the observed incentive mix), but often fail to explain a broader pattern of empirical evidence. From this, it is also clear that a richer setup exploring additional dimensions of the management toolbox, such as employee screening in the recruitment process, demotions, career concern incentives, and so forth, may produce additional testable predictions about employees' careers. In this respect, our analysis paves the way for future research.

\section{References}

Abraham, K.G., and H.S. Farber. 1987. “Job Duration, Seniority, and Earnings,”77 American Economic Review 278-97.

Altonji, J.G., and C.R. Pierret. 2001, "Learning and Statistical Discrimination,”116 Quarterly Journal of Economics 313-50.

Altonji, J.G., and R.A. Shakotko. 1987. "Do Wages Rise with Job Seniority?"54 Review of Economic Studies 437-59.

Baker, G.P., M. Gibbs, and B. Holmström. 1994a. "The Internal Economics of the Firm: Evidence from Personnel Data,"109 Quarterly Journal of Economics 881-919.

—. 1994b. "The Wage Policy of the Firm," 109 Quarterly Journal of Economics 921-55.

Farber, H.S., and R. Gibbons. 1996. "Learning and Wage Dynamics,"111 Quarterly Journal of Economics 1007-47.

Farrall, C., and B. Shearer. 1999. "Incentives and Transactions Costs within the Firm: Estimating an Agency Model Using Payroll Records,"66 Review of Economic Studies 309-38.

Frederiksen, A., B.E. Honoré, and L. Hu. 2007. "Discrete Time Duration Models with GroupLevel Heterogeneity,"141 Journal of Econometrics 1014-43.

Gibbons, R.S., and L. Katz. 1991. "Layoffs and Lemons," 9 Journal of Labor Economics 351-80.

Gibbons, R.S., and M. Waldman. 1999a. "A Theory of Wage and Promotion Dynamics Inside Firms,"114 Quarterly Journal of Economics 1321-58.

- 1999b. "Careers in Organizations: Theory and Evidence,"in O. Ashenfelter and D. Card, eds., Handbook of Labor Economics, 3B, Ch. 35, pp. 2373-37. Amsterdam: Elsevier.

Gibbs, M. 1995. "Incentive Compensation in a Corporate Hierarchy,"19 Journal of Accounting and Economics 247-77.

Guasch, J.L., and A. Weiss. 1980. "Wages as a Sorting Mechanism in Competitive Markets with Asymmetric Information: A Theory of Testing," 47 Review of Economic Studies 653-64.

Holmström, B. 1979. "Moral Hazard and Observability,"9 Bell Journal of Economics 74-91. . 1982. "Moral Hazard in Teams,"13 Bell Journal of Economics 324-40.

Lange, F. 2007. “The Speed of Employer Learning,"25 Journal of Labor Economics 1-35.

Lazear, E.P. 1986. "Salaries and Piece Rates,"59 Journal of Business 405-31.

1992. "The Job as a Concept," in W. Bruns, ed., Performance Measurement, Evaluations, and Incentives, 183-215. (Boston, MA: Harvard University Press).

- 2000. "Performance Pay and Productivity,"90 American Economic Review 1346-61.

Lazear, E.P., and S. Rosen. 1981. "Rank-Order Tournaments as Optimum Labour Contracts,"89 Journal of Political Economy 841-64.

Lazear, E.P., and K. Shaw. 2008. "Tenure and Output,"15 Labour Economics 705-24.

MacLeod, W. B. 2003. “Optimal Contracting with Subjective Evaluation,”93 American Economic Review 216-40.

MacLeod, W.B., and J.M. Malcolmson. 1998. "Motivation and Markets,"88 American Economic Review 388-411.

Medoff, J., and K. Abraham. 1980. "Experience, Performance, and Earnings,”95 Quarterly Journal of Economics 703-36. 
1981. “Are Those Paid More Really More Productive?"16 Journal of Human Resources $186-216$.

Mirrlees, J. 1974. "Notes on Welfare Economics, Information, and Uncertainty,"in M. Balch, D. McFadden, and S. Wu, eds., Essays on Economic Behavior under Uncertainty , 243-58. Amsterdam, The Netherlands: North Holland.

- 1976. "The Optimal Structure of Incentives and Authority within an Organization," 7 Bell Journal of Economics 105-31.

Shapiro, C., and J. E. Stiglitz. 1984. "Equilibrium Unemployment as a Worker Discipline Device,"74 American Economic Review 433-44.

Topel, R. 1991. "Specific Capital, Mobility, and Wages: Wages Rise with Job Seniority,”99 Journal of Political Economy 145-176.

Waldman, M. 1984. "Job Assignments, Signalling and Efficiency,"15 The RAND Journal of Economics 255-267. 